\title{
Nail psoriasis as a severity indicator: results from the PsoReal study
}

This article was published in the following Dove Press journal:

Patient Related Outcome Measures

22 December 2010

Number of times this article has been viewed

\author{
Marc A Radtke' \\ Anna K Langenbruch' \\ Ines Schäfer' \\ Katharina Herberger ${ }^{\prime}$ \\ Kristian Reich ${ }^{2}$ \\ Matthias Augustin' \\ 'Institute for Health Services \\ Research in Dermatology and \\ Nursing, University Medical Center \\ of Hamburg-Eppendorf, Hamburg; \\ ${ }^{2}$ Dermatologikum Hamburg, Germany
}

Correspondence: Marc Alexander Radtke Institute for Health Services Research in Dermatology and Nursing, Competenzzentrum Versorgungsforschung in der Dermatologie, Cvderm, Universitätsklinikum Hamburg-Eppendorf, Martinistrasse 52, 20246 Hamburg, Germany

Tel +49040 74I 055428

Fax +49040 74I 055348

Email m.radtke@uke.de
Background: Although nail psoriasis affects a substantial proportion of psoriasis patients and causes significant psychologic distress, few epidemiologic data characterizing patients with nail involvement are available. The aim of this research was to elucidate differences between patients with nail psoriasis and those without any nail involvement, taking quality indicators of health care from the patient's perspective into account.

Methods: In total, 2449 patient members of the Deutscher Psoriasis Bund, the largest patient organization for psoriasis in Germany, were interviewed in this nationwide, noninterventional, cross-sectional study. Patients with nail psoriasis were compared with patients without any nail involvement with regard to gender, age, disease duration, affected body surface area, healthrelated quality of life (Dermatology Life Quality Index [DLQI] ED-5D), patient-defined treatment benefit, amount of inpatient treatments, disease duration, and numbers of work days lost.

Results: Data from 2449 patients with psoriasis were analyzed. Overall, 44.8\% (1078) of patients were female, mean age was $57.0 \pm 11.7$ years, and $72.8 \%$ had nail involvement and showed higher values for affected body surface area than those without nail involvement ( $8.3 \%$ versus $5.6 \%$, respectively; $P<0.004$ ). Health-related quality of life was significantly lower in patients with nail psoriasis (DLQI 7.2 versus 5.3; ED-5D 60.1 versus 67.3), who had more days off work (9.8 versus 3.3 ).

Conclusion: Nail involvement is an important symptom of psoriasis and is associated with greater disease severity and quality of life impairment. Accordingly, management of psoriasis should include a special focus on nail involvement.

Keywords: psoriasis, nails, quality of life, health services research, quality indicators

\section{Introduction}

Nail involvement is associated with significant physical and psychological consequences for a substantial number of psoriasis patients. ${ }^{1}$ Prevalence data for nail involvement in psoriasis vary between $10 \%$ and $55 \% .^{2-4}$ The prevalence rises to $70 \%-80 \%$ in cases where joint involvement is also present. ${ }^{2,3}$ The clinical spectrum is very heterogeneous depending on involvement of the nail bed, matrix, or folds, and includes pitting, grooving, and stippling, as well as discoloration, leukonychia, and onychodystrophy ranging to onycholysis. ${ }^{4}$ Combined nail matrix and nail bed psoriasis can develop in cases of very severe inflammation, a possible consequence of which is the formation of only parakeratotic, crumbly material by the matrix and bed, a condition referred to as "psoriatic crumbly nail". 5 This finding constitutes a risk factor for secondary mycotic infections, which can occur in up to $27 \%$ of psoriasis patients, and calls for more detailed diagnostic tests and therapy adapted to the findings. ${ }^{6}$ Nail psoriasis is submit your manuscript $\mid$ www.dovepress.com

Dovepress

DOI: $10.2147 /$ PROM.SI 4861
Patient Related Outcome Measures 201 I:2 I-6

(C) 20I I Radtke et al, publisher and licensee Dove Medical Press Ltd. This is an Open Access article which permits unrestricted noncommercial use, provided the original work is properly cited. 
associated with a prolonged duration of psoriasis itself ${ }^{7}$ and greater severity of skin and joint involvement, and may also be an indicator for the activity of psoriatic arthritis. ${ }^{8}$ Both psoriasis and psoriatic arthritis, and by implication, psoriatic nail disease, have been considered as autoimmune disorders. McGonagle et $\mathrm{al}^{9}$ contributed important microanatomic and genetic insights which suggest that an aberrant response to tissue stressing of the integrated nail-joint apparatus, rather than autoimmunicity, is driving the inflammatory process. The nail is functionally linked to the distal phalanx and several distal interphalangeal joint structures, including extensor tendon fibers and the collateral ligaments. ${ }^{10}$

In a large number of psoriasis patients, skin involvement, as well as nail involvement, leads to significant impairment of quality of life. ${ }^{11-14}$ This is due to physical symptoms, psychologic burden, and limitations at work ${ }^{11,12}$ and at leisure. Psoriasis on visible areas of the body may give rise to stigmatization in everyday life. ${ }^{13}$ The economic implications of nail psoriasis have not previously been the specific subject of studies, though individual cost-of-illness studies have drawn attention to this problem. ${ }^{14,15}$

Treatment of nail psoriasis can be challenging for both the dermatologist and patient. ${ }^{16}$ Owing to the slow growth of the nail plate, response to therapy can sometimes take years. A therapeutic response in the areas of the nail matrix and nail bed has been described for vitamin D analogs and highly potent topical steroids in liquid form. ${ }^{7,17,19}$ However, the feasibility of topical therapy is limited by the difficulty in achieving adequate antipsoriatic concentrations at the site of the inflammatory process. ${ }^{18} \mathrm{~A}$ faster, better, and more sustained response to therapy in nail psoriasis has been described for systemic therapeutics and in particular for biologics. ${ }^{19-22}$ In the largest clinical study so far published on the systemic treatment of psoriasis, infliximab was found to be a highly effective therapy for nail psoriasis over the long term. ${ }^{27}$

Although it can be assumed that nail psoriasis constitutes a significant health problem for patients, there have so far been only a few studies from Germany in which disease severity and quality of life of patients with nail psoriasis were examined. The data acquired to date were collected via dermatologic centers and clinics, ${ }^{31-33}$ which may suggest selection and response bias.

The aim of this study was to characterize patients with nail psoriasis in comparison with patients without any nail involvement and to determine profiles of patients with nail psoriasis, including quality of life, by collecting relevant data from patients of the Deutscher Psoriasis Bund, the largest patient organization for psoriasis in Germany.

\section{Materials and methods Study design}

This cross-sectional study involved the collection of health care-related data by standardized questionnaires. The target variables included defined care indicators analogous to those of an earlier study (PsoHealth 2007). ${ }^{19}$ The conception and coordination of the study were under the auspices of the Competence Centre for Health Services Research in Dermatology (University Clinics of Hamburg) in cooperation with the Professional Association of German Dermatologists and the German Dermatological Society. Ethical approval was obtained from the Institutional Review Board.

\section{Recruitment}

Patient recruitment was done via the Deutscher Psoriasis Bund. Questionnaires were sent to all members of this organization as a supplement to the March 2008 edition of the PsoMagazine. A total of 6923 questionnaires were distributed nationwide. After obtaining informed consent, the completed questionnaires were returned to the Competence Centre for Health Services Research in Dermatology by post. Patients were admitted to the study if they were suffering from medically verified psoriasis and were at least 18 years of age.

\section{Variables}

Sociodemographic data, health insurance status, case history of psoriasis and psoriatic arthritis, past and present treatments, patient-defined therapeutic benefit, number of inpatient treatments for psoriasis in the previous 5 years, number of office visits, days off work, and health-related quality of life were assessed. The patient filled in a body diagram with a box grid to indicate the affected body area. Disease-specific (dermatologic) quality of life was measured using the Dermatology Life Quality Index (DLQI), which consists of 10 items. General health-related quality of life was determined using the visual analog scale from Euroqol (EQ-5D), whereby the patient grades his/her current state of health on a scale from 0 ("worst imaginable state of health") to 100 ("best possible state of health").

\section{Statistical analysis}

Data entry was performed by means of double entries in Excel files using plausibility tests. Congruence of the entries was checked by matrix subtraction. In case of discrepancy, 
an independent coder determined the correct entry using the original questionnaires. Results of the survey were evaluated using SPSS Version 17 for Windows. All data were described using standard statistical parameters (absolute and percentile frequencies for categoric data; mean value, standard deviation for continuous data). Nonparametric Mann-Whitney $U$-tests or unpaired $t$-tests were carried out to compare the results from the different patient groups. Alpha errors were adjusted using a Bonferroni correction. Due to the large sample size, each $t$-test was complemented by effect-size determination (d) to qualify the mean difference through the averaged standard deviation. Effect sizes of 0.2, 0.5, and 0.8, respectively, represent weak, medium, and strong effects in unpaired $t$-tests. ${ }^{20}$

\section{Results \\ Sociodemographic data}

Of the 6923 questionnaires distributed, a total of 2489 were returned within the study period (35.4\%). After exclusion of invalid questionnaires, data sets amenable to evaluation were available from $2449(98.4 \%)$ patients. The mean age of the patients was $57.0 \pm 11.7$ years (Table 1$), 44.8 \%(\mathrm{n}=1078)$ were female, $52.7 \%(\mathrm{n}=1289)$ were in paid work, and $71.1 \%$

Table I Characteristics of study population $(n=2449)$

\begin{tabular}{|c|c|c|c|}
\hline & $\mathbf{n}$ & $\%$ & $\begin{array}{l}\text { Mean age } \pm \text { SD } \\
\text { (range 18-92) }\end{array}$ \\
\hline Female & 1078 & 44.8 & $57.0 \pm 11.7$ \\
\hline Male & 1326 & 55.2 & $55.5 \pm 12.0$ \\
\hline Total $^{\mathrm{a}}$ & 2404 & 100.0 & $57.0 \pm 11.7$ \\
\hline Partnership/marriage & 1740 & 71.1 & n.a. \\
\hline \multicolumn{4}{|l|}{ Level of education } \\
\hline $\begin{array}{l}\text { Without school } \\
\text { completion certificate }\end{array}$ & 9 & 0.4 & n.a. \\
\hline Secondary school & 619 & 25.3 & n.a. \\
\hline Secondary modern school & 738 & 30.1 & n.a. \\
\hline High school & 990 & 40.4 & n.a. \\
\hline School for special education & 2 & 0.1 & n.a. \\
\hline Other undefined education & 48 & 2.0 & n.a. \\
\hline \multicolumn{4}{|l|}{ Working life } \\
\hline Employed & 1289 & 52.7 & n.a. \\
\hline Not currently working & 1159 & 47.3 & n.a. \\
\hline \multicolumn{4}{|l|}{ Current treatment } \\
\hline Biologics & 190 & 7.8 & n.a. \\
\hline Systemic treatment & 599 & 24.5 & n.a. \\
\hline Topical steroids & 333 & 13.6 & n.a. \\
\hline Topical vitamin $D_{3}$ analogs & 323 & 13.2 & n.a. \\
\hline UV treatment & 548 & 22.4 & n.a. \\
\hline PUVA treatment & 71 & 2.9 & n.a. \\
\hline Topical skin care products & 460 & 18.8 & n.a. \\
\hline
\end{tabular}

Notes: aMissing value for gender in 45 patients, missing value for age in 20 patients. Abbreviations: PUVA, psoralen combined with ultraviolet A; UV, ultraviolet; n.a., not available; SD, standard deviation. $(n=1740)$ were married. On average, the initial diagnosis of psoriasis had been 34.0 years earlier.

\section{Clinical characteristics of patients with and without nail psoriasis}

Of the patients who responded, $72.8 \%$ reported nail involvement. The mean duration of psoriasis did not differ significantly between patients with and without nail psoriasis (34.3 years versus 33.0 years, respectively, Table 2). Patients with nail psoriasis reported a significantly greater area of affected skin ( $8.3 \%$ versus 5.6\% affected body area; $P<0.001)$ and displayed a significantly lower quality of life in the DLQI (7.2 versus 5.3; $P<0.001)$ and a poorer state of health in the EQ5-D (60.1 versus 67.3; $P<0.001)$. The number of days off work was significantly higher in patients with nail psoriasis $(9.8$ versus $3.3 ; P<0.001)$. Mean patient-defined therapeutic benefit was slightly higher in patients without nail psoriasis (2.4 versus 2.3). Patients with nail psoriasis displayed significantly worse values for satisfaction with their treatment, stress, and time expenditure due to therapy. These differences remained significant even after Bonferroni correction. The mean number of consultations was significantly higher in nail psoriasis patients, both with dermatologists and with orthopedic surgeons/ rheumatologists (Table 3).

\section{Discussion}

The aim of the present study was to analyze predefined clinical and socioeconomic characteristics of patients with nail psoriasis versus patients without nail involvement in Germany. The background of this study is the special importance of nail involvement as a stigmatizing factor and as a variable in long-term therapy planning. ${ }^{12-15,30}$ The method of direct data collection from patients, who were also members of the Deutscher Psoriasis Bund, a self-help organization, without approaching their attending doctors, was chosen deliberately in order to achieve a patient cohort selected differently from the means of data access used in previous studies. ${ }^{34}$ An added benefit of this method was the exclusion of bias from "social desirability" of officebased practice.

The present data allow the hypothesis-generating assumption that nail involvement in psoriasis might be a predictor of a more severe course of the disease. The visibility of nail involvement and the associated stigmatization could, moreover, be an important determinant of reduced quality of life, although this might also be poorer because the body is affected to a much greater degree in patients with nail psoriasis. 
Table 2 Comparison between psoriasis patients with and without nail involvement $(n=2449)$

\begin{tabular}{|c|c|c|c|c|c|c|c|c|}
\hline \multirow[t]{2}{*}{ Variable } & \multicolumn{3}{|c|}{ No nail psoriasis } & \multicolumn{3}{|c|}{ Nail psoriasis } & \multirow[t]{2}{*}{$P^{c}$} & \multirow[t]{2}{*}{$d^{d}$} \\
\hline & $\mathbf{n}$ & Mean & SD & Mean & SD & $\mathbf{n}$ & & \\
\hline Years since initial diagnosis & 607 & 33.0 & 16.1 & 34.3 & 13.9 & 1730 & 0.089 & 0.08 \\
\hline Affected body area (\%) & 621 & 5.5 & II.I & 8.3 & 14.9 & 1753 & $<0.00 I^{* *}$ & 0.21 \\
\hline Quality of life (DLQI) & 621 & 5.3 & 5.3 & 7.2 & 6.4 & $|76|$ & $<0.00$ I*** & 0.33 \\
\hline EQ-5D: State of health $(0-100)$ & 611 & 67.3 & 21.0 & 60.1 & 21.6 & 1747 & $<0.00 I^{* * *}$ & 0.34 \\
\hline $\begin{array}{l}\text { Number of inpatient treatments } \\
\text { for psoriasis in previous } 5 \text { years }\end{array}$ & 95 & 3.0 & 4.5 & 3.5 & 6.0 & 442 & 0.445 & 0.09 \\
\hline $\begin{array}{l}\text { Days off work due to psoriasis in } \\
\text { previous } 12 \text { months }\end{array}$ & 339 & 3.3 & 15.9 & 9.8 & 42.0 & 936 & $<0.00 I^{*}$ & 0.2 \\
\hline PBI total score (weighted) & 589 & 2.4 & $\mathrm{I} . \mathrm{I}$ & 2.3 & I.I & 1671 & $0.004 *$ & 0.14 \\
\hline $\begin{array}{l}\text { Satisfaction with previous } \\
\text { psoriasis treatment }{ }^{\mathrm{a}}\end{array}$ & 604 & 2.0 & 0.8 & 2.2 & 0.8 & 1722 & $<0.001 *$ & 0.21 \\
\hline Treatment regarded as a burden ${ }^{\mathrm{b}}$ & 511 & 1.8 & 1.2 & 2.1 & 1.2 & 1534 & $<0.00 I^{*}$ & 0.21 \\
\hline $\begin{array}{l}\text { Treatment is associated with } \\
\text { great time expenditure }{ }^{b}\end{array}$ & 509 & 1.7 & 1.3 & 1.9 & 1.3 & $|53|$ & $0.001 *$ & 0.17 \\
\hline
\end{tabular}

Notes: ${ }^{a}\left(I=\right.$ very satisfied to $4=$ very unsatisfied); ${ }^{b}(I=$ not at all to $5=$ very $)$; clevel of significance in $t$-test for independent samples; ${ }^{d}$ effect size; $*$ significant after Bonferroni correction at the $P<0.05$ level; **highly significant after Bonferroni correction at the $P<0.01$ level; ***highly significant after Bonferroni correction at the $P<0.00$ I level.

Abbreviations: DLQI, Dermatology Life Quality Index; EQ-5D, Euroqol; PBI, patient-defined treatment benefit; SD, standard deviation.

The data from the present study confirm the results of two earlier health care studies conducted in dermatology practices in Germany, ${ }^{21,22,30}$ in which nail involvement in psoriasis was likewise associated with more severe forms of the disease, particularly with regard to the incidence of joint involvement and impairment of quality of life. ${ }^{23}$ In this study, nail psoriasis was diagnosed in $40.9 \%$ of the patients, and those with nail involvement also had a longer disease duration (21.9 versus 18.1 years), higher disease severity (mean Psoriasis Area Severity Index 12.7 versus 9.3), higher frequency of psoriatic arthritis (26.0\% versus $12.7 \%$ ), more impairment of health-related quality of life (mean Dermatology Life Quality Index 8.9 versus 7.3), and a 2.5 -fold higher rate of inpatient treatment.

Table 3 Frequency of consultations due to psoriasis $(n=2366)^{a}$

\begin{tabular}{|c|c|c|c|c|c|}
\hline & \multicolumn{2}{|c|}{ No nail psoriasis } & \multicolumn{2}{|c|}{ Nail psoriasis } & \multirow[t]{2}{*}{$P^{c}$} \\
\hline & Mean & SD & Mean & SD & \\
\hline \multicolumn{6}{|c|}{ Office visits in last 12 months } \\
\hline Dermatologist $\mathrm{t}^{\mathrm{b}}$ & 1.7 & 1.3 & 2.0 & 1.4 & $<0.00 I^{*}$ \\
\hline Internal specialist ${ }^{\mathrm{b}}$ & 0.6 & 0.9 & 0.8 & 1.1 & $<0.00 I^{*}$ \\
\hline $\begin{array}{l}\text { Orthopedic } \\
\text { surgeon/ } \\
\text { rheumatologist }^{\mathrm{b}}\end{array}$ & 0.8 & 1.0 & I.I & 1.1 & $<0.00 I^{*}$ \\
\hline $\begin{array}{l}\text { General } \\
\text { practitioner }^{b}\end{array}$ & 1.9 & 1.1 & 2.1 & 1.2 & $<0.00 I^{*}$ \\
\hline
\end{tabular}

Notes: ${ }^{a}$ Data with regard to a therapist in those cases in which any office visit frequency was entered were counted as "no visits"; $n=52$ (no entry regarding a doctor); $\mathrm{n}=31$ (no entry regarding nail involvement); ${ }^{b}$ within the last 12 months, $0=$ no doctor visits, $I=1-2$ times, $2=3-5$ times, $3=6-10$ times, $4 \geq 10$ times; 'due to the ordinal scaled variable a nonparametric Mann-Whitney $U$-test was calculated; *still significant after Bonferroni correction.

Abbreviation: SD, standard deviation.
Any interpretation of the results must take account of the fact that, although a reasonable geographic distribution of participating patients was achieved, the possibility that patients with a high level of suffering and severe disease may actively seek the support of a patient organization such as the Deutscher Psoriasis Bund. Thus, selection bias cannot be ruled out here. Moreover, the mean age of the patients and their duration of disease were significantly higher in the present study than in the preceding PsoHealth studies from 2005 and 2007. The reason for this might be that patients with long-standing disease, and all its frustrations, are more likely to join a patient organization and to remain members for a longer period of time. A further limitation of this approach is the lack of differentiation between patients with nail involvement and patients with psoriatic arthritis, who often show both disease manifestations at the same time. Data concerning work time lost due to psoriasis may not reflect differentiation between the different clinical aspects.

There is no doubt that nail involvement in psoriasis constitutes not only a cosmetic problem, but also an important part of the complex inflammatory process of psoriasis. The importance of this is further underscored by the association between nail psoriasis and psoriatic arthritis ${ }^{33}$ and by the significant comorbidity of psoriasis with metabolic syndrome and other chronic inflammatory autoimmune diseases. ${ }^{24,25}$ Therefore, the aim of future health care studies of nail psoriasis should be to examine the extent to which the nature and intensity of nail involvement affects quality indicators of the severity of psoriasis under "real-world" conditions. 


\section{Conclusion}

Nail involvement is an important symptom of psoriasis and is associated with greater disease severity and quality of life impairment. Accordingly, management of psoriasis should include a special focus on nail involvement. Should the results of the present study, albeit at present only hypothesisgenerating, be confirmed, further studies should be conducted to determine the extent to which the severity of nail involvement might serve as a predictor for the identification of high-need patients. In the event that nail psoriasis proves to have predictive value, it could, like psoriatic arthritis, be an indicator of need for early systemic therapy to avert serious progression of the disease.

\section{Acknowledgment}

We are grateful to the Deutscher Psoriasis Bund, Hamburg, for its cooperation in the planning and data collection for this study.

\section{Disclosure}

This study received financial support from Essex Pharma GmbH Munich, Germany. MAR, KR, and MA are conducting or have conducted clinical studies and act or have acted as advisers for Essex Pharma.

\section{References}

1. Lawry M. Biological therapy and nail psoriasis. Dermatol Ther. 2007;20:60-67.

2. Farber EM, Nall L. Nail psoriasis. Cutis. 1992;50:174-178.

3. Van Laborde S, Scher RK. Developments in the treatment of nail psoriasis, melanonychia striata, and onychomycosis. A review of the literature. Dermatol Clin. 2000;18:37-46.

4. Augustin M, Krüger K, Radtke MA, Schwippl I, Reich K. Disease severity, quality of life and health care in plaque-type psoriasis: a multicenter cross-sectional study in Germany. Dermatology. 2008;216 366-372.

5. Leung YY, Tam LS, Kun EW, Li EK. Psoriatic arthritis as a distinct disease entity. J Postgrad Med. 2007;53:63-71.

6. Williamson L, Dalbeth N, Dockerty JL, Gee BC, Weatherall R, Wordsworth BP. Extended report: nail disease in psoriatic arthritis - clinically important, potentially treatable and often overlooked. Rheumatology. 2004;43:790-794.

7. Reich K, Krüger K, Mössner R, Augustin M. Epidemiology and clinical pattern of psoriatic arthritis in Germany: a prospective interdisciplinary epidemiological study of 1511 patients with plaque-type psoriasis. Br J Dermatol. 2009;160:1040-1047.

8. Jiaravuthisan MM, Sasseville D, Vender RB, Murphy F, Muhn CY. Psoriasis of the nail: anatomy, pathology, clinical presentation, and a review of the literature on therapy. J Am Acad Dermatol. 2007; $57: 1-27$.

9. Baran R. The burden of nail psoriasis. An introduction. Dermatology. 2010;221:1-5.

10. Gupta AK, Lynde CW, Jain HC, Sibbald RG, Elewski BE, Daniel CR 3rd, Watteel GN, Summerbell RC. A higher prevalence of onychomycosis in psoriatics compaired with non-psoriatics: a multicentre study. $\mathrm{Br} J$ Dermatol. 1997;136:786-789.
11. de Jong EM, Seegers BA, Gulinck MK, Boezeman JB, van de Kerkhof PC. Psoriasis of the nails associated with disability in a large number of patients: results of a recent interview with 1,728 patients. Dermatology. 1996;193:300-303.

12. Augustin M, Ogilvie A. Methods of outcomes measurement in nail psoriasis. Dermatology. 2010;221_23-28.

13. Wilson FC, Icen M, Crowson CS, McEvoy MT, Gabriel SE, Kremers HM. Incidence and clinical predictors of psoriatic arthritis in patients with psoriasis: a population-based study. Arthritis Rheum. 2009;61:233-239.

14. Gupta AK, Cooper EA. Psoriatic nail disease: quality of life and treatment. J Cutan Med Surg. 2009;13:S102-S106.

15. Krueger G, Koo J, Lebwohl M, Menter A, Stern RS, Rolstad T. The impact of psoriasis on quality of life: results of a 1998 National Psoriasis Foundation patient-membership survey. Arch Dermatol. 2001;137:280-284.

16. De Arruda LH, De Moraes AP. The impact of psoriasis on quality of life. Br J Dermatol. 2001;144 Suppl 58:33-36.

17. Zachariae R, Zachariae H, Blomqvist K, Davidsson S, Molin L, Mørk C, Sigurgeirsson B. Quality of life in 6497 Nordic patients with psoriasis. Br J Dermatol 2002;146:1006-1016.

18. Chan B, Hales B, Shear N, Ho V, Lynde C, Poulin Y, Mittmann N. Work-related lost productivity and its economic impact on Canadian patients with moderate to severe psoriasis. J Cutan Med Surg 2009;13:192-197.

19. Fowler JF, Duh MS, Rovba L, Buteau S, Pinheiro L, Lobo F, Sung J, Doyle JJ, Swensen A, Mallett DA, Kosicki G. The impact of psoriasis on health care costs and patient work loss. J Am Acad Dermatol. 2008;59:772-780

20. Sohn S, Schoeffski O, Prinz J, Reich K, Schubert E, Waldorf K, Augustin M. Cost of moderate to severe plaque psoriasis in Germany: a multicenter cost-of-illness study. Dermatology. 2006;212: 137-144.

21. Berger K, Ehlken B, Kugland B, Augustin M. Cost-of-illness in patients with moderate and severe chronic psoriasis vulgaris in Germany. J Dtsch Dermatol Ges. 2005;3:511-518.

22. Yu AP, Tang J, Xie J, Wu EQ, Gupta SR, Bao Y, Mulani PM. Economic burden of psoriasis compared to the general population and stratified by disease severity. Curr Med Res Opin. 2009;25:2429-2438.

23. Feldman SR, Fleischer AB Jr, Reboussin DM, Rapp SR, Bradham DD, Exum ML, Clark AR. The economic impact of psoriasis increases with psoriasis severity. J Am Acad Dermatol. 1997;37:564-569.

24. Kacar N, Ergin S, Erdogan BS. The comparison of nail psoriasis severity index with a less time-consuming qualitative system. J Eur Acad Dermatol Venereol. 2008;22:219-222.

25. Tosti A, Piraccini BM, Cameli N, Kokely F, Plozzer C, Cannata GE, Benelli C. Calcipotriol ointment in nail psoriasis: a controlled double blind comparison with bethametasone dipropionate and salicylic acid. Br J Dermatol. 1998;139:655-659.

26. Wozel G. Psoriasis treatment in difficult locations: scalp, nails, and intertriginous areas. Clin Dermatol. 2008;26:448-459.

27. Rich P, Griffiths CE, Reich K, Nestle FO, Scher RK, Li S, Xu S, Hsu MC, Guzzo C. Baseline nail disease in patients with moderate to severe psoriasis and response to treatment with infliximab during 1 year. J Am Acad Dermatol. 2008;58:224-231.

28. Noiles K, Vender R. Nail psoriasis and biologics. J Cutan Med Surg. 2009; $13: 1-5$

29. Luger TA, Barker J, Lambert J, Yang S, Robertson D, Foehl J, Molta CT, Boggs R. Sustained improvement in joint pain and nail symptoms with etanercept therapy in patients with moderate-to-severe psoriasis. J Eur Acad Dermatol Venereol. 2009;23:896-904.

30. Reich K. Approach to managing patients with nail psoriasis. J Eur Acad Dermatol Venereol. 2009;23 Suppl 1:15-21.

31. Augustin M, Krüger K, Radtke MA, Schwippl I, Reich K. Disease severity, quality of life and health care in plaque-type psoriasis: a multicenter prospective cross-sectional study in Germany. Dermatology. 2008;216:366-372. 
32. Augustin M, Reich K, Blome C, Schäfer I, Laass A, Radtke MA. Nail psoriasis in Germany - epidemiology, clinical characteristics and burden of disease. Br J Dermatol. 2010;163:580-585.

33. Augustin M, Reich K, Reich C, Purwins S, Rustenbach SJ, Schaefer I, Radtke MA. Quality of psoriasis care in Germany - results of the national study PsoHealth 2007. J Dtsch Dermatol Ges. 2008;6: 640-645.
34. Augustin M, Reich K, Glaeske G, Schaefer I, Radtke M. Comorbidity and age-related prevalence of psoriasis - analysis of health insurance data from more than 1.3 million persons in Germany. Acta Derm Venereol. 2010;90:147-151.

35. Ortonne JP, Baran R, Corvest M, Schmitt C, Voisard JJ, Taieb C. Development and validation of nail psoriasis quality of life scale (NPQ10). J Eur Acad Dermatol Venereol. 2010 Jan;24(1):22-27.

\section{Publish your work in this journal}

Patient Related Outcome Measures is an international, peer-reviewed, open access journal focusing on treatment outcomes specifically relevant to patients. All aspects of patient care are addressed within the journal and practitioners from all disciplines are invited to submit their work as well as healthcare researchers and patient support groups. Areas covered will include: Quality of life scores; Patient satisfaction audits; Treatment outcomes that focus on the patient; Research into improving patient outcomes; Hypotheses of interventions to improve outcomes; Short communications that illustrate improved outcomes; Case reports or series that show an improved patient experience; Patient journey descriptions or research.

\footnotetext{
Submit your manuscript here: http://www.dovepress.com/patient-related-outcome-measures-journal
} 